\title{
Optimal geographic diversification and firm performance: Evidence from the
}

\section{U.K}

Nigel Driffield*, Jun Du* and Sourafel Girma ${ }^{+i}$

*Economics and Strategy Group, Aston Business School, Aston University, Birmingham

B4 7ET. n.1.Driffield@aston.ac.uk j.du@aston.ac.uk

\author{
${ }^{+}$Nottingham University Business School, \\ Jubilee Campus, \\ Nottingham, \\ NG8 1BB. \\ Sourafel.girma@,nottingham.ac.uk
}

\begin{abstract}
This paper examines the relationship between multinationality and firm performance. The analysis is based on a sample of over 400 UK multinationals, and encompasses both service sector and manufacturing sector multinationals. This paper confirms the non-linear relationship between performance and multinationality that is reported elsewhere in the literature, but offers further analysis of this relationship.

Specifically, by correcting for endogeneity in the investment decision, and for shocks in productivity across countries, the paper demonstrates that the returns to multinationality are greater than those that have been reported elsewhere, and persist to higher degrees of international diversification.
\end{abstract}

JEL codes: F23, D24

Keywords: multinationality, performance, productivity 


\section{Introduction:}

For some twenty years now, international business scholars, following Porter (1986) and Bartlett and Ghoshal (1986) have identified increasing multinationality as a crucial response to increasing global competition. Multinationality protects firms from exchange rate swings, and enables faster responses to changes in local demand. Zaheer and Manrakhan (2001) for example identify a large increase in the geographic dispersion in services, similar to the findings of UNCTAD (2004). This is attributed to the greater scope for the use of international networks within the firm, easing international coordination. However, one key question remains unanswered; whether increased multinationality stems from the greater opportunity to capture location advantages, or whether FDI has replaced trade as coordination costs have fallen.

Traditionally, the analysis of performance of the multinational enterprise (MNE) or its subsidiaries has focussed on the ability of firms to generate and control firm specific assets, exploiting them across national boundaries. This work is largely founded on Dunning's (1988) well known 'ownership advantages' explanation of FDI. This presumes that the MNE possesses some form of technological superiority; thus where a company has some competitive advantage over its rivals, and where for reasons of property rights protection licensing is unsafe, a company will set up production facilities in a foreign country through FDI. The caveat to this is simply that there are specific advantages in the host country which make FDI preferable to exporting.

More recently, following Dunning (1998) some focus has turned the importance of location. Much of the analysis concerning the importance of location within the OLI framework has traditionally been concerned with the ability of the firm to acquire raw materials by becoming multinational, and then subsequently on the ability of the firm to identify locations with lower labour costs. More recently however, analysis has turned to a wider range of location factors, both in explaining location of FDI, and also the relationships between location and performance, see for example Coughlin and Segev (2000). Many regions now see the attraction of FDI as being the most 
efficient way to connect to global markets for both finished and intermediate products as well as new technology. In turn, firms have responded to these policy initiatives from various regional or national development agencies and become increasingly diversified geographically. Work that seeks to link multinationality to performance attempts to determine how widely such technology can be managed and exploited before returns start to decline. However, it is important here to distinguish between tangible firm-specific assets, and more intangible assets, which by their nature are harder to exploit through the market mechanism. The importance of intangible assets in relating multinationality to performance is often ignored.

\section{The importance of location and firm performance}

As Dunning (1998) points out, international coordination of activity is becoming ever easier, and while trade growth has exceeded output growth globally, both have been far outstripped by FDI growth. Equally, there is now significant evidence that in excess of $50 \%$ of trade between developed countries is intra-firm trade, see for example UNCTAD $(1998,2002,2004)$. Production in the developed world is becoming characterised by the increased clustering of activity, with subsidiaries of multinationals looking to interact with local clusters in order to assimilate local competencies. This has been shown to be important for productivity growth, not only within the multinationals, but also within the domestic sector, see for example De Propris and Driffield (2005). Such issues are coming to be seen in the context of "technology sourcing", that is where firms engage in FDI, not merely to exploit their firm specific assets in new markets, but also acquire or assimilate knowledge from the host country, see for example Cantwell and Piscitello (2005), Siotis (1999) or in the theoretical economics literature Fosfuri and Motta (1999). More recently, Belderbos and Sleuwaegen (2005) demonstrate that competition, both at home and abroad, and the speed of technological change has increased the scale and scope multinational activity at the firm level in recent years. 
While this issues discussed here can be applied in most developed and transition economies of the world, the focus here will be the UK. The UK offers a particularly interesting and important case when evaluating the importance of multinationality, as many UK firms are highly diversified internationally, and have been so for a long time. By the end of 2000, U.K MNEs owned over£600 billion worth of assets abroad. Figure 1 illustrates the scale and scope of multinational activity by UK firms.

\section{Figure 1. here}

Given the interest in explaining this phenomenon, and the scale of outward FDI carried out by UK firms, it is perhaps surprising that research on geographic diversification (i.e. degree of multinationality) and corporate performance of U.K MNEs is rather limited. One possible explanation for this is that empirically it becomes difficult to distinguish the causal relationship between multinationality and performance. In other words there exists a standard endogeneity problem that numerous researchers in the international business literature have addressed with varying degrees of success. Doukas and Lang (2003) for example suggest that the distinction should be made between core, and non-core FDI. They illustrate that in allowing for this, the returns to "core" (non-diversified) FDI become greater than would otherwise be the case. Largely however this focuses on the response of the secondary equity market to the announcement of FDI, which may also be subject to asymmetric information bias.

\section{Previous analysis of multinationality and performance}

While there is a well developed literature that compares performance between domestic and foreign owned operations in a given location, the literature on multinationality and performance is less clear. This literature can be traced back to Grant (1987) and Ramaswamy (1995), and is based on a variety of approaches, with various statistical methods of varying degrees of sophistication. Perhaps not surprisingly the results from previous studies are rather mixed. Previous analysis 
suggests several reasons why increased multinationality should be linked to firm performance, see for example Kogut (1985), Benvignati (1987); Grant (1987); Gomes and Ramaswamy (1999) and Contractor et al.(2003). These include: (i) better access to technological knowledge and foreign product innovation; (ii) wider international networks and management structure to meet domestic competition; (iii) benefits from economies of scale and scope; (iv) dampening the impact of domestic business fluctuations by using foreign market outlets; (v) taking advantage of factor cost differentials across multiple locations; (vi) tapping into corporate specific strategies such as transfer pricing and tax accounting practices; and (vii) greater geographic dispersion which facilitates the undertaking of domestic ventures that are high-risk but also highly profitable.

This literature however has also identified several reasons as to why the costs associated with expanding abroad might outweigh the potential benefits. For example, Grant (1987) suggests that bounded rationality will limit the capacity of managers to cope successfully with greater complexity associated with multinationality. In turn, this will be reflected in increased multinationality exerting a negative impact on performance. Hitt et al. (1997) also argue that multinationality may generate a decline in performance due to excessive spreading of managerial capabilities and co-ordination problems. Based on similar arguments, Greniger et al. (1989) hypothesise an quadratic relationship between the degree of multinationality and performance. In the same vein, Gomes and Ramaswamy (1999) contend that above a threshold level of multinationality, transactional and informational costs may exceed the benefits of diversification. In a similar vein, Mathur et al. (2001) point out that due to potentially high initial costs of establishing abroad, there might be an initial performance decline followed by improvements, as average costs decline once economies of scale and scope are achieved. Similar results are reported by Tallman and Li (1995), who effectively report a negative effect on profits for being a multinational, but a positive effect in terms of the number of countries. This again highlights the problem of endogeneity discussed above. Berry (2002) reports similar results, but identifies different effects 
depending on the location of international activities. Kotabe et al. (2002) offer a different interpretation of these varied results, arguing that the relationship between multinationality and performance depends on numerous firm specific factors, such that there exists significant heterogeneity in the data. In turn, they identify one of the fundamental problems in this type of analysis, significant information asymmetry between the researcher and the management of the firm. Ideally, the firm will know what its scope for increasing performance will be, based on developing technology, new market opportunities etc, while the researcher will only be able to proxy this, based on past levels of R\&D, advertising, and investment, etc.

This suggests two important considerations when seeking to link multinationality to firm performance. Firstly, there will be significant differences in performance (profitability) across industries, and also potentially a good deal of variation between firms. As such, studies based on relatively small samples must be treated with caution. Secondly, decisions taken by firms with respect to becoming multinational cannot be divorced from the decision making of the firm overall. This is perhaps best illustrated by decisions of firms concerning investment in new capital. It is perfectly feasible that a firm may decide to substitute domestic investment for foreign investment, which may artificially boost profitability at home.

We therefore offer two extensions on the previous literature. Firstly we allow for differences in the effects across industries, and secondly offer a comparison between the manufacturing and non-manufacturing sectors. In common with a great deal of firm level analysis, much of the focus in this literature is in the manufacturing sector. This is largely due historically to the availability of data, but this is unsatisfactory given the growth in importance of the service sector. Capar and Kotabe (2004) and Contractor et al. (2003) address the issue of service sector multinationals. Both papers report a non linear relationship between multinationality and performance, and both employ relatively large samples. Again, both papers focus on profitability, 
while Contractor et al. (2003) employ panel data and allow for inter-industry effects in performance.

Kotabe et al. (2002) suggest that an important consideration in the relationship between multinationality and performance is the technological or R\&D intensity of the firm. They argue that R\&D intensive firms or firms in high technology industries will not only be best able to become multinational, but also best placed to exploit the advantages of multinationality. Further, several authors, for example Kotabe et al. (2002), Belderbos and Sleuwagen (2005) and Tallman and Li (1996) highlight the importance of inter-industry effects in this relationship, and discuss the importance of this in the context of industry level characteristics. Indeed, this is consistent with the recent literature on technology sourcing and the location of $\mathrm{R} \& \mathrm{D}$, see for example Cantwell and Piscitello (2005), suggesting that FDI is associated with technological development in the source as well as host country. This suggests that the relationship between multinationality and performance will vary with industry or firm level technological intensity. Low tech firms have potentially the greatest number of host countries available to them, and as such are able to identify low cost locations. However, while the coordination of low level activities across geographical space is relatively easy, the economies of scale associated with most low tech activities would suggest that geographical diversification will be limited. Conversely, the resource-based theory would suggest that high technology firms are well placed to coordinate international activities, but across a more limited number of available locations. Firms in medium technology industries however are more likely to experience the benefits of coordinating technology flows across countries, while at the same time having a wider range of potential locations.

In much of the literature, these effects are captured using dummy variables for the various industries in the sample. This however is potentially unsatisfactory, as the relationship between multinationality and performance may vary across industries. We therefore offer two further extensions to the existing literature. In addition to distinguishing between service sector and 
manufacturing sector FDI, we also test for differences in the results by the level of technology. This is done by distinguishing between firms in "high, medium and low" technology industries "ii

\section{Hypotheses}

Our fundamental hypothesis is that geographic diversification in the form of outward FDI, is positively related to firm performance at home. However, this increases at a decreasing rate. Further, in contrast to much of the previous work in this area, most multinationals, rather than having diversified internationally to the point of diminishing returns, actually have scope for further expansion leading to greater productivity gains.

Subsidiary hypotheses then relate to the other variables that control for differences in performance. Industry concentration for example is associated with lower levels of productivity, while exporting is associated with productivity growth. The ownership of intangible assets is strongly related to the performance of MNEs, and is therefore expected to be positive. In a similar vein we hypothesise different effects across not only services and manufacturing. Multinationality is expected to be more important for high tec firms, who are able to gain from international management of technology, outsource low value added activities, and access technology generated abroad.

\section{Empirical methodology.}

Following much of the literature discussed above, we begin by postulating a nonlinear relationship between multinationality and performance. However, rather than focussing on profitability, which may be beset by several sources of bias, we focus on productivity at the firm level. This has numerous advantages. Firstly, an important consideration in the context of the MNE is that technology developed in the home country (or elsewhere in the MNE) and then transferred to the UK may therefore change the technology available to the foreign subsidiary, and increase productivity. If the costs of $R \& D$ are borne in a particular location (and despite evidence that $R \& D$ 
is becoming more global, a high proportion of the typical firm's R\&D is still undertaken at home) then this will depress measures of profitability, unless this is allowed for in the estimation. Further, as is well documented, profitability at the firm or even industry level is always susceptible to shocks, and equally depressed profitability at home may be the factor that encourages firms to undertake FDI. Again, if these issues are not allowed for, then the results generated will tend to be biased. A second consideration is that shocks may be country specific, such that MNEs with exposure to certain countries may for the short term demonstrate higher or lower levels of performance depending on the shock. With short time series and small samples, this could explain why there is a high degree of variability of the results in the literature seeking to link multinationality to performance.

As is discussed above, a potential problem with much of the analysis in this area is that it is beset by endogeneity, simultaneity or the reverse causality problem. This arises from informational asymmetry between the firms' managers and the econometrician. The former has a good knowledge of the firm's performance and will make use of this knowledge in the choice of inputs. By contrast the econometrician can only observe the firm's inputs (typically from the firm's balance sheet) and traditionally assumes that performance is uncorrelated with input choices. This erroneous assumption may lead to biased estimates. This paper therefore adopts an alternative approach.

Firstly, we focus on a sample of UK multinationals. This removes the concern that is often expressed with work of this type, that a positive relationship between multinationality and productivity may be the result of more productive firms becoming multinational, rather than the opposite. Secondly, we propose a method for estimating (total factor) productivity (TFP) based on Levinsohn and Petrin (2003) ${ }^{\mathrm{iii}}$. In general, one can think of productivity (or indeed profitability) as the outcome from a series of structural equations (a production or cost function in the case of productivity, and the interaction between the firms production / cost function and the market demand function in the case of profitability). Productivity is then assumed to be uncorrelated with 
inputs. This assumption is unlikely to be valid in the presence of productivity shocks, as profitmaximizing firms will expand their output in case of positive productivity shock, and thus naturally require additional inputs. In the case of a negative shock, firms will cut back output, and hence require fewer inputs. Ignoring this endogeneity, as traditional approaches do, risks generating biased estimates of productivity. The Levinsohn and Petrin (2003) ${ }^{\text {iv }}$ method alleviates this problem, by utilizing intermediate inputs to proxy for the unobserved productivity shock. Estimates of firm-level TFP obtained using this approach account for this endogeneity bias stemming from the correlation between unobservable productivity shocks and input levels.

This is an important consideration in the context of international business research, as this makes explicit allowance for the fact that input choices depend upon firm efficiency. This method is explained in more detail in the appendix. It is easy to envisage how this may be an important consideration in the analysis of the MNE, following the seminal work of Griliches and Maireisse (1995). For example, it is possible that productivity shocks may be industry but not country specific, such that any analysis of performance based on relatively short time series (while Contractor et al. (2003) employ five years data, much of the literature in this area is based only on cross-sectional data) will fail to capture this, either over or under estimating the multinationality effect.

In order to isolate the impact of the degree of multinationality on performance, we therefore focus on productivity estimation. This has the advantage of being able to correct for many of the sources of bias discussed above, that would be present if we focussed on profitability. This renders the possibility of spurious correlation far less likely, and focuses on a much tighter definition of performance.

$$
T F P_{i t}=\beta^{\prime} X_{i t}+f(M U L T)+\text { time dummies }+\varepsilon_{i t}
$$

In the above equation $\mathrm{i}$, and $\mathrm{j}$ index firms and time periods respectively; $\mathrm{X}$ is a vector of other factors that are hypothesised to impact on firms' performance. It consists of a number of firm 
level and industry level variables. At the level of the firm we include export intensity, defined as the share of exports in total sales, (see for example, Girma et al., 2004), the ratio of intangible assets to fixed assets and a measure of industry diversification (proxied by the number of five-digit industries the firm operates in). The intangible assets variable is taken from the firms' company accounts. Braunerhjelm (1996) argues that intangible assets more closely correspond to the theoretical notion of 'firm specific assets'. The level of industrial diversification is considered important here. This is clearly distinct from geographic diversification, while capturing the ability of the firm to manage disparate assets. Bodnar et al., (2000) for example illustrate that studies which seek to measure the effects of geographic diversification, without allowing for industry level diversification, tend to produce misleading results.

Further, our model incorporates two theoretically important variables: imports penetration ${ }^{\mathrm{v}}$ to capture potential efficiency-enhancing effects of international product market competition (see for example Levinshon, 1993) and a Herfindhal index of industry concentration. There is significant evidence that firms with a high degree of market power demonstrate lower levels of efficiency, see for example Nickell (1996). This is an important consideration often omitted in this literature, which is perhaps rather surprising given the importance attached to work such as Hymer (1976) and Kindleberger (1969) in other areas of international business. Finally it is assumed that the random error $\varepsilon$ is distributed independently distributed from the explanatory variables.

In order to examine the relationship between multinationality and performance, we begin by following Contractor et al. (2003) and others, and postulate a nonlinear relation between total factor productivity and multinationality:

$$
f(M U L T) \equiv \gamma=d_{1} M U L T+d_{2} M U L T^{2}
$$


Where the d's are parameters to be estimated. Setting $d_{2}=0$ gives the linear model, which implies that productivity either increases or decreases with the degree multinationality monotonically. The quadratic specification is more flexible in that it allows for the rate at which productivity increases to vary with the degree of multinationality, as measured by the geographic dispersion of the firm. For example with $d_{1}>0$ and $d_{2}<0$, the initially positive impact of multinational on productivity will start to diminish once the degree of multinationality gets past the critical level $\delta=-\frac{d_{1}}{2 d_{2}}$, assuming that there are degree multinationality values greater than $\delta$. The asymptotic variance of this turning point can be constructed via the so-called Delta method, given consistent estimates of $d_{1}$ and $d_{2}\left(\hat{d}_{1}\right.$ and $\left.\hat{d}_{2}\right)$, and can be expressed as

$$
\operatorname{Var}(\hat{\delta})=\frac{1}{4 \hat{d}_{2}^{2}}\left[\operatorname{var}\left(\hat{d}_{1}\right)+4 \hat{\delta} \operatorname{cov}\left(\hat{d}_{1}, \hat{d}_{2}\right)+4 \hat{\delta}^{2} \operatorname{var}\left(\hat{d}_{2}\right)\right]
$$

Equation 1 is first estimated via ordinary least squares, allowing for heteroskedasticity and within-firm serial correlation. This is essentially a conditional mean regression, providing an estimate of the geographic diversification effects on performance.

However, standard techniques that concentrate on the conditional mean function of the dependent variable are unlikely to be adequate analytical tools in the presence of heterogeneous productivity processes. This point is made, albeit in a different context by Kotabe et al. (2002), who refer to inter-industry effects. We offer a significant extension to this, by considering the median regression technique. This is a special case of the semi-parametric method of quantile regressions (see Buchinski, 1998, for an excellent review of the literature). This involves solving the following minimisation problem where $\mathrm{Z}$ represents all explanatory variables, and the $\beta$ terms are the coefficients. 


$$
\min _{\beta} \frac{1}{n}\left\{\sum_{i, t:}\left|\Delta T F P_{i t}-Z_{i t}^{\prime} \beta\right|\right\}
$$

$(4)^{\mathrm{vi}}$

Another problem frequently encountered in estimation relates to outliers. This is particularly important in the context of multinationality, for reasons discussed above. For example, it is possible that country specific shocks in host countries will impact on firms operating in those countries, while others remain unaffected. If useful generalisations are to be drawn, it is important to ensure that the results reflect what is going on in the majority of the sample rather than being driven by a few outlying observations. For this reason we also deploy a third estimation strategy in this study: outlier robust regression (Rousseeuw and Leroy, 1987).

\section{Data and main findings:}

The two main sources of information for this study are the European Linkages and International Ownership Structure (ELIOS) database built at the University of Urbino ${ }^{\mathrm{vii}}$, and the OneSource database of private and public companies, which is derived from the accounts that companies are legally required to deposit at Companies House. OneSource includes information on all public limited companies, all companies with employees greater than 50, and the top companies based on turnover, net worth, total assets, or shareholders funds (whichever is largest) up to a maximum of 110,000 companies, in both manufacturing and service industries. OneSource provides information on employment, physical capital, output and cost of goods sold in a consistent way both across firms and across time, and nominal aggregates were deflated using five-digit level industry deflator. However, OneSource does not provide any information on the multinational activity of U.K-owned firms. For this reason it was necessary to merged it with ELIOS, which is based on information from Dun \& Bradstreet's Who Owns Whom and Bureau Van Dijck's 
Amadeus. The sample resulting from the merging of the OneSource and ELIOS contains necessary information on 409 UK multinationals enterprises over the period 1990-1999 .

Table 1 reports some summary statistics for the main variables of interest.

\section{Table 1 here}

The average UK multinational in the sample operates in about 5 countries and 4 industries, although there is substantial heterogeneity in the sample. The firms in the sample are large, employing more than 5000 workers on average. The average export intensity is also quite high, standing at more than $84 \%$.

The results from the econometric estimations are reported in Table 2. The coefficients on the exporting intensity and intangible assets variables are positive in all specifications. This is consistent with the notion that exporting and the possession of firm specific assets are generally associated with the more productive enterprises. Conditional on geographic diversification, industrial diversification and import competition do not appear to exert any discernible influence on the productivity of the firms. By contrast firms in highly concentrated industry exhibit a lower level of efficiency, all else being equal.

\section{Table 2 here}

In line with the literature discussed above, we find significant evidence of non-linearity in the relationship between multinationality and performance. However, in contrast to previous results, our regression estimates provide robust evidence of an inverted U-shaped relationship between efficiency level and the degree of multinationality, as measured by the number of countries the firms operate in. The degree of multinationality and TFP are positively related up to a threshold point beyond which a further increase in the number of countries the firm operates in is associated with declining level of efficiency. The conditional mean (i.e. OLS) and the outlier robust models suggest that this threshold value is around 25 countries. For the outlier robust model, for example, the $95 \%$ confidence interval of this threshold value is between 20 and 29 countries. In the 
median regression the corresponding confidence interval is between 19 and 27 countries. The raw data shows that only $5 \%$ of the firms have subsidiaries in more than 20 countries, and combined with our econometric results, this would appear to suggest that for the vast majority of UK MNEs a further increase in their geographic diversification is likely to lead to additional efficiency gains. The threshold values for the level of multinationality at which point productivity begins to decrease are larger than reported elsewhere. There two essential reasons for this. Firstly, we have a larger sample of firms than much of the previous literature in this area, such that the industry level effects discussed by Kotabe et al. (2002) can be adequately addressed, as can the issues of outliers, and sources of performance shocks, due to the methodology described above. It should also be stressed that our sample consists of large multinationals, rather than a random sample of firms. On the one hand, this alleviates that sample selection bias, in that all firms are already multinationals, but on the other it potentially overstates the benefits of multinationality in general.

In practice, while there are some firms that do have very wide dispersion, the mean number of countries that a firm has a presence in is less than five, and so for most firms the impact of multinationality on performance is positive. It should also be stressed that while the optimal number of countries for a firm to is a s high as 29 for some subsamples, this presumes that there exist that many additional investment opportunities comparable with those observed in the data.

We have also explored if overseas manufacturing subsidiaries have a different impact on the performance of parent companies compared with their service sector counterparts. To this end we estimate two versions of model (1) by altering the definition of geographic diversification to include either manufacturing or non-manufacturing only. The results from these experiments are reported in Tables 3 and 4, and they indicate that the nonlinear relationship between geographic diversification and performance is generally not sensitive to the activities of the foreign subsidiaries.

\section{Tables 3 and 4 here}


Turning now to the samples of firms distinguished by the level of technology employed, tables 5-8 all demonstrate the quadratic relation between multinationality and performance. The results for the low tech and medium-low tech sectors are very similar to the overall manufacturing sample, demonstrating the importance of export intensity and intangible assets as well as multinationality. The optimal degree of multinationality suggested by these results is 20 countries however, smaller than the result for the full sample. However, if one considers table 7 , the mediumhigh tech sectors, then optimal multinationality increases dramatically, suggesting that the returns to multinationality are greater for this sector.

\section{Tables 5-8 here}

Finally, the results reported in table 8 , the high tech sectors confirms the hypothesis suggested by Kotabe et al.(2002) and Hitt et al.(1996) derived from the resource based view of the firm. The returns to multinationality are greatest for this group, in the sense that the coefficient on the "degree of multinationality" variable is greater than for the other sub samples, but that the optimal number of locations is smaller (15), due to the limited number of suitable locations for these firms. This also offers an explanation of a result reported elsewhere in the literature, though seldom explored, that highly internationalised firms eventually experience negative returns to multinationality, see for example Contractor et al.(2003). It is well documented that FDI is most prevalent in technologically intensive industries, but clearly the optimal number of countries for such firms is lower than for less technology intensive firms.

Table 9 offers some perspective of the importance of the turning point, the point at which the returns to multinationality begin to decline. We present here the proportions of the four subsamples that been actually reached optimal point, and those that reach the minimum value of the $95 \%$ confidence interval. It is clear from this, that few firms reach the point at which returns to multinationality decline. While, in common with other research discussed above, we find a non- 
linear relationship between multinationality and performance; in practical terms few firms reach the point at which the non-linearity becomes pertinent. 


\section{Conclusion}

This paper has investigated the relationship between geographic diversification and corporate performance based on a panel of more than 400 UK MNEs. After controlling for a host of firm level and industry factors that affect performance, we find a robust positive correlation between the degree of multinationality and productive efficiency. However, the relationship between geographic expansion and productivity is not monotonic: the diversification effect starts to decline after some threshold level of multinationality. However the overwhelming majority of UK MNES are found to be operating below the estimated optimal level of multinationality, suggesting that they may have ample scope for further exploiting their firm-specific assets through increased geographic diversification.

The results presented here are broadly in line with the previous literature, though we are able to identify more clearly the thresholds in the relationship between multinationality and performance. In allowing for productivity shocks, and outliers in the analysis, we are able to identify more clearly the relationship between multinationality and performance, particularly in the context of the non-linearity and the threshold effects. For most firms, there is considerable scope for further geographic diversification before they face any real concerns about negative returns to multinationality. This suggests that previous studies reporting only small returns to FDI may be undervaluing the potential returns to the firm, and may explain why Doukas and Lang (2003) report adverse reactions from equity markets, especially to diversified FDI. 


\section{Appendix A \\ The semiparametric approach to estimating TFP}

This study estimates firm level total factor productivity using the semiparametric approach of Levinshon and Petrin (2003), which is an extension of Olley and Pakes (1996). The major advantage of this approach over more traditional production function estimation techniques is its ability to more effectively control for the correlation between unobservable productivity shocks and input. Olley and Pakes (1996) address the endogeneity problem by employing investment as a proxy (instrument) for productivity shocks. The reason why investment is correlated with unobserved (to the econometrician) productivity is simple. An establishment with a larger productivity shock this year will invest more than an otherwise similar establishment with a smaller realised productivity shock, because it expects to do better in the future. This method hinges on the crucial assumption that the relationship between investment and productivity is monotonic, implying investment is valid proxy for firms reporting non-zero. But firm level investment is usually lumpy (because of adjustment costs), and Levinshon and Petrin (2003) suggest the use intermediate inputs as proxies (i.e. to control for unobservable productivity shocks). They argue that intermediate inputs are less costly to adjust, and thus may respond more fully to productivity shocks.

For estimation purposes we employ a Cob-Douglas production function we write the valueadded based production function for firm $i$ at time $t$ as:

$$
\begin{aligned}
y_{i t} & =\beta_{0}+\beta_{l} l_{i t}+\beta_{k} k_{i t}+\omega_{i t}+\varepsilon_{i t} \\
& \equiv \beta_{l} l_{i t}+\phi_{t}\left(k_{i t}, m_{i t}\right)+\varepsilon_{i t}
\end{aligned}
$$

where $\mathrm{y}$ is $\log$ of value added, which is defined as sales, net of intermediate inputs (m), 1 is labour input and $\mathrm{k}$ is capital input, and $\phi_{t} \equiv \phi_{t}\left(k_{i t}, \omega_{i t}\right)=\beta_{0}+\beta_{k} k_{i t}+\omega_{i t}\left(k_{i t}, m_{i t}\right)$ is an unknown function of capital and intermediate inputs. $\phi_{t}$ is strictly increasing in the productivity shock $\omega_{i t}$, so that it can be inverted and one can write $\omega_{i t}=\omega_{t}\left(i_{i t}, k_{i t}\right)$ for some function $\omega_{t}$.

Levinshon and Petrin (2003) approximate $\phi_{t}\left(k_{i t}, m_{i t}\right)$ by a third order polynomial in $\mathrm{k}$ and $\mathrm{m}$, $\sum_{j=0}^{3} \sum_{s}^{3} \delta_{j s} k_{i t}^{j} m_{i t}^{s}$ and obtain and estimate of $\beta_{l}$ and $\phi_{t}$ (up to the intercept) via OLS. This constitutes the first stage of the estimation procedure. At the second stage the elasticity of capital $\beta_{k}$ is defined as the solution to $\min _{\beta_{k}^{*}} \sum_{i} \sum_{t}\left(y_{i t}-\hat{\beta}_{l} l_{i t}-\beta_{k}^{*} k_{i t}-\varpi_{i t}\right)^{2}$, where $\varpi_{i t}$ is a nonparametric approximation $E\left[\omega_{i t} \mid \omega_{i t-1}\right]$. Since the estimators involve two stages the calculations of the covariance matrix of 
the parameters must allow for the variation due to all of the estimators in the two stages. Levinshon and Petrin (2003) note that the derivation of the analytical covariance matrix is quite involved, and suggest the use the bootstrap to estimate standard errors. In this study 250 bootstrap replications are performed. Once consistent estimates of the input elasticities are at hand, log of productivity can be obtained as $\hat{\omega}_{i t}=y_{i t}-\hat{\beta}_{l} l_{i t}-\hat{\beta}_{k} k_{i t}$.

Appendix B: Classification of manufacturing industries by level of technology intensity.

\begin{tabular}{|c|c|}
\hline Level of technology intensity & NACE two digits code (Divisions) \\
\hline High-technology sectors & $\begin{array}{l}\text { Manufacture of office machinery and computers } \\
(30) ; \text { Manufacture of radio, television and } \\
\text { communication equipment and apparatus( } 32) \text {; } \\
\text { Manufacture of medical, precision and optical } \\
\text { instruments, watches and clocks (33). }\end{array}$ \\
\hline Medium-high technology sectors & $\begin{array}{l}\text { Manufacture of electrical machinery and apparatus } \\
\text { n.e.c. (31); Manufacture of motor vehicles, trailers } \\
\text { and semi-trailers (34); Manufacture of chemicals } \\
\text { and chemical products (24); Manufacture of } \\
\text { machinery and equipment n.e.c. (29); Manufacture } \\
\text { of other transport equipment (35) }\end{array}$ \\
\hline Medium-low technology sectors & $\begin{array}{l}\text { Manufacture of coke, refined petroleum products } \\
\text { and nuclear fuel (23); Manufacture of rubber and } \\
\text { plastic products (25); Manufacture of other non- } \\
\text { metallic mineral products (26); Manufacture of } \\
\text { basic metals (27); Manufacture of fabricated metal } \\
\text { products, except machinery and equipment (28) }\end{array}$ \\
\hline Low technology sectors & $\begin{array}{l}\text { Manufacture of food products and beverages (15); } \\
\text { Manufacture of tobacco products (16); Manufacture } \\
\text { of textiles (17); Manufacture of wearing apparel; } \\
\text { dressing and dyeing of fur (18); Tanning and } \\
\text { dressing of leather; manufacture of luggage, } \\
\text { handbags, saddlery, harness and footwear (19); } \\
\text { Manufacture of wood and of products of wood and } \\
\text { cork, except furniture; manufacture of articles of } \\
\text { straw and plaiting materials (20); Manufacture of } \\
\text { pulp, paper and paper products (21); Publishing, } \\
\text { printing and reproduction of recorded media (22); } \\
\text { Manufacture of furniture; manufacturing n.e.c. (36) } \\
\text { Recycling (37) }\end{array}$ \\
\hline
\end{tabular}

Source: Eurostat-OECD classification of technology-intensive sectors 
Table 1

Summary statistics

\begin{tabular}{|l|l|l|}
\hline & Mean & $\begin{array}{l}\text { Standard } \\
\text { deviation }\end{array}$ \\
\hline $\begin{array}{l}\text { Number of five-digit industries } \\
\text { firm operates }\end{array}$ & 3.51 & 1.76 \\
\hline Export intensity & 0.844 & 0.313 \\
\hline Employment & 5194.7 & 20048.9 \\
\hline Real sales (£' 000) & 465429.3 & 1981385 \\
\hline Intangible/fixed assets & 0.199 & 1.378 \\
\hline Log of total factor productivity & 0.070 & 0.492 \\
\hline $\begin{array}{l}\text { Number of countries firm } \\
\text { operates in }\end{array}$ & 4.62 & 6.53 \\
\hline
\end{tabular}

Note: The number of firms is 409 and the above figures are based on 3252 firm-year observations

Table 2

The relationship between geographic diversification and performance.

\begin{tabular}{|l|l|l|l|}
\hline & $\begin{array}{l}\text { OLS with robust } \\
\text { standard errors }\end{array}$ & $\begin{array}{l}\text { Median } \\
\text { regression }\end{array}$ & $\begin{array}{l}\text { Outlier robust } \\
\text { regression }\end{array}$ \\
\hline Industry concentration & -0.339 & -0.337 & -0.289 \\
& $(2.43)^{*}$ & $(4.58)^{* *}$ & $(4.69)^{* *}$ \\
\hline Imports competition & -0.084 & 0.002 & -0.016 \\
& $(0.89)$ & $(0.06)$ & $(0.44)$ \\
\hline Export intensity & 0.114 & 0.164 & 0.119 \\
& $(2.10)^{*}$ & $(6.94)^{* *}$ & $(6.01)^{* *}$ \\
\hline Intangible assets & 0.054 & 0.075 & 0.109 \\
& $(6.76)^{* *}$ & $(15.04)^{* *}$ & $(25.22)^{* *}$ \\
\hline Industry diversification & 0.003 & 0.006 & 0.003 \\
& $(0.26)$ & $(1.33)$ & $(0.86)$ \\
\hline Degree of multinationality & 0.029 & 0.031 & 0.029 \\
& $(4.51)^{* *}$ & $(9.18)^{* *}$ & $(10.23)^{* *}$ \\
\hline Square of Degree of & -0.001 & -0.001 & -0.001 \\
multinationality & $(2.75)^{* *}$ & $(5.74)^{* *}$ & $(5.90)^{* *}$ \\
\hline Observations & 3252 & 3252 & 3252 \\
\hline R-squared & 0.09 & & 0.26 \\
\hline
\end{tabular}

All regressions include time dummies, Robust t-statistics in parentheses *significant at 5\%; ** significant at $1 \%$ 
Table 3

The relationship between geographic diversification and performance:

Non-manufacturing subsidiaries only

\begin{tabular}{|l|l|l|l|}
\hline & $\begin{array}{l}\text { OLS with robust } \\
\text { standard errors }\end{array}$ & Median regression & $\begin{array}{l}\text { Outlier robust } \\
\text { regression }\end{array}$ \\
\hline Industry concentration & -0.320 & -0.293 & -0.270 \\
& $(2.30)^{*}$ & $(4.72)^{* *}$ & $(4.40)^{* *}$ \\
\hline Imports competition & -0.078 & -0.006 & -0.011 \\
& $(0.82)$ & $(0.17)$ & $(0.32)$ \\
\hline Export intensity & 0.125 & 0.170 & 0.128 \\
& $(2.30)^{*}$ & $(8.58)^{* *}$ & $(6.58)^{* *}$ \\
\hline Intangible assets & 0.054 & 0.074 & 0.107 \\
& $(6.67)^{* *}$ & $(17.48)^{* *}$ & $(24.93)^{* *}$ \\
\hline Industry diversification & 0.004 & 0.007 & 0.004 \\
& $(0.39)$ & $(2.09)^{*}$ & $(1.19)$ \\
\hline Degree of multinationality & 0.034 & 0.035 & 0.033 \\
& $(4.15)^{* *}$ & $(10.29)^{* *}$ & $(9.74)^{* *}$ \\
\hline Square of Degree of & -0.001 & -0.001 & -0.001 \\
multinationality & $(2.30)^{*}$ & $(5.55)^{* *}$ & $(4.99)^{* *}$ \\
\hline Observations & 3252 & 3252 & 3252 \\
\hline R-squared & 0.09 & ---- & 0.26 \\
\hline All regressions & & & \\
\hline
\end{tabular}

All regressions include time dummies, Robust t-statistics in parentheses *significant at 5\%;** significant at $1 \%$

Table 4

The relationship between geographic diversification and performance: Manufacturing subsidiaries only

\begin{tabular}{|l|l|l|l|}
\hline & OLS & Median regression & $\begin{array}{l}\text { Outlier robust } \\
\text { regression }\end{array}$ \\
\hline Industry concentration & -0.318 & -0.312 & -0.271 \\
& $(2.31)^{*}$ & $(5.35)^{* *}$ & $(4.33)^{* *}$ \\
\hline Imports competition & -0.084 & 0.021 & -0.017 \\
& $(0.88)$ & $(0.64)$ & $(0.47)$ \\
\hline Export intensity & 0.122 & 0.173 & 0.133 \\
& $(2.22)^{*}$ & $(9.20)^{* *}$ & $(6.63)^{* *}$ \\
\hline Intangible assets & 0.053 & 0.077 & 0.104 \\
& $(6.81)^{* *}$ & $(18.68)^{* *}$ & $(23.72)^{* *}$ \\
\hline Industry & 0.004 & 0.009 & 0.005 \\
diversification & $(0.38)$ & $(2.53)^{*}$ & $(1.27)$ \\
\hline Degree of & 0.035 & 0.035 & 0.032 \\
multinationality & $(4.17)^{* *}$ & $(10.02)^{* *}$ & $(8.41)^{* *}$ \\
\hline Square of Degree of & -0.001 & -0.001 & -0.001 \\
multinationality & $(1.87)$ & $(5.84)^{* *}$ & $(3.93)^{* *}$ \\
\hline Observations & 3252 & 3252 & 3252 \\
\hline R-squared & 0.09 & ---- & 0.24 \\
\hline All regressions & & & \\
\hline
\end{tabular}

All regressions include time dummies, Robust t-statistics in parentheses *significant at 5\%;** significant at $1 \%$ 
Table 5

The relationship between geographic diversification and performance: Low tech intensity sector

\begin{tabular}{|l|l|l|l|}
\hline & OLS & median & outlier robust \\
\hline Industry concentration & -1.406 & -0.960 & -0.997 \\
& $(4.14)^{* *}$ & $(5.82)^{* *}$ & $(6.44)^{* *}$ \\
\hline Imports competition & -0.540 & -0.484 & -0.497 \\
& $(2.61)^{*}$ & $(4.77)^{* *}$ & $(5.34)^{* *}$ \\
\hline Export intensity & 0.048 & 0.115 & 0.112 \\
& $(0.49)$ & $(2.75)^{* *}$ & $(2.91)^{* *}$ \\
\hline Intangible assets & 0.061 & 0.093 & 0.126 \\
& $(5.01)^{* *}$ & $(15.53)^{* *}$ & $(23.13)^{* *}$ \\
\hline Industry & 0.000 & 0.001 & -0.003 \\
diversification & $(0.02)$ & $(0.18)$ & $(0.38)$ \\
\hline Degree of & 0.021 & 0.028 & 0.020 \\
multinationality & $(1.42)$ & $(4.18)^{* *}$ & $(3.21)^{* *}$ \\
\hline Square of Degree of & -0.000 & -0.001 & -0.000 \\
multinationality & $(1.01)$ & $(3.31)^{* *}$ & $(2.21)^{*}$ \\
\hline Optimal point & $\mathbf{2 5}$ & $\mathbf{2 0}$ & $\mathbf{2 3}$ \\
\hline Observations & 807 & 807 & 807 \\
\hline R-squared & 0.15 & ---- & 0.48 \\
\hline
\end{tabular}

All regressions include time dummies, Robust t-statistics in parentheses *significant at 5\%;** significant at $1 \%$

Table 6

The relationship between geographic diversification and performance: Medium-low tech intensity sector

\begin{tabular}{|l|l|l|l|}
\hline & OLS & median & outlier robust \\
\hline Industry concentration & 0.161 & -0.189 & 0.025 \\
& $(0.59)$ & $(2.30)^{*}$ & $(0.27)$ \\
\hline Imports competition & 0.240 & 0.161 & 0.141 \\
& $(1.65)$ & $(2.73)^{* *}$ & $(2.21)^{*}$ \\
\hline Export intensity & 0.114 & 0.109 & 0.070 \\
& $(1.27)$ & $(3.44)^{* *}$ & $(2.08)^{*}$ \\
\hline Intangible assets & 0.034 & 0.069 & 0.062 \\
& $(1.14)$ & $(6.67)^{* *}$ & $(4.39)^{* *}$ \\
\hline Industry & 0.021 & 0.025 & 0.026 \\
diversification & $(1.63)$ & $(4.74)^{* *}$ & $(4.54)^{* *}$ \\
\hline Degree of & 0.030 & 0.030 & 0.024 \\
multinationality & $(2.73)^{* *}$ & $(5.93)^{* *}$ & $(4.40)^{* *}$ \\
\hline Square of Degree of & -0.001 & -0.001 & -0.001 \\
multinationality & $(2.19)^{*}$ & $(4.12)^{* *}$ & $(2.86)^{* *}$ \\
\hline Optimal point & $\mathbf{1 9}$ & $\mathbf{1 9}$ & $\mathbf{2 1}$ \\
\hline Observations & 666 & 666 & 666 \\
\hline R-squared & 0.19 & ---- & 0.21 \\
\hline
\end{tabular}

All regressions include time dummies, Robust t-statistics in parentheses

$*$ significant at $5 \% ; * *$ significant at $1 \%$ 
Table 7

The relationship between geographic diversification and performance: Medium-high tech intensity sector

\begin{tabular}{|l|l|l|l|}
\hline & OLS & median & outlier robust \\
\hline Industry concentration & -0.020 & -0.045 & -0.057 \\
& $(0.12)$ & $(0.46)$ & $(0.65)$ \\
\hline Imports competition & 0.110 & 0.100 & 0.087 \\
& $(1.08)$ & $(1.83)$ & $(1.80)$ \\
\hline Export intensity & 0.055 & 0.100 & 0.063 \\
& $(0.59)$ & $(2.83)^{* *}$ & $(2.00)^{*}$ \\
\hline Intangible assets & 0.046 & 0.078 & 0.099 \\
& $(2.43)^{*}$ & $(7.77)^{* *}$ & $(5.95)^{* *}$ \\
\hline Industry & -0.014 & -0.016 & -0.019 \\
diversification & $(0.90)$ & $(2.50)^{*}$ & $(3.40)^{* *}$ \\
\hline Degree of & 0.033 & 0.035 & 0.031 \\
multinationality & $(3.27)^{* *}$ & $(7.72)^{* *}$ & $(7.90)^{* *}$ \\
\hline Square of Degree of & -0.001 & -0.001 & -0.000 \\
multinationality & $(1.61)$ & $(3.46)^{* *}$ & $(3.15)^{* *}$ \\
\hline Optimal point & 32 & 33 & 37 \\
\hline Observations & 1185 & 1185 & 1184 \\
\hline R-squared & 0.11 & ---- & 0.21 \\
\hline All & &
\end{tabular}

All regressions include time dummies, Robust t-statistics in parentheses

$*$ significant at $5 \%$; * significant at $1 \%$

Table 8

The relationship between geographic diversification and performance: High tech intensity sector

\begin{tabular}{|l|l|l|l|}
\hline & OLS & median & outlier robust \\
\hline Industry concentration & -0.454 & -0.168 & 0.378 \\
& $(0.49)$ & $(0.45)$ & $(1.27)$ \\
\hline Imports competition & -0.316 & 0.004 & 0.117 \\
& $(0.72)$ & $(0.03)$ & $(1.19)$ \\
\hline Export intensity & 0.252 & 0.261 & 0.189 \\
& $(1.65)$ & $(3.95)^{* *}$ & $(3.55)^{* *}$ \\
\hline Intangible assets & -0.004 & 0.029 & 0.136 \\
& $(0.07)$ & $(2.86)^{* *}$ & $(3.83)^{* *}$ \\
\hline Industry & 0.017 & 0.021 & 0.020 \\
diversification & $(0.59)$ & $(1.53)$ & $(1.78)$ \\
\hline Degree of & 0.060 & 0.055 & 0.063 \\
multinationality & $(2.39)^{*}$ & $(3.67)^{* *}$ & $(5.20)^{* *}$ \\
\hline Square of Degree of & -0.002 & -0.002 & -0.002 \\
multinationality & & & \\
\hline & $(1.81)$ & $(2.20)^{*}$ & $(3.46)^{* *}$ \\
\hline Optimal point & $\mathbf{1 4}$ & $\mathbf{1 5}$ & $\mathbf{1 3}$ \\
\hline Observations & 594 & 594 & 593 \\
\hline R-squared & 0.11 & ---- & 0.24 \\
\hline
\end{tabular}

All regressions include time dummies, Robust t-statistics in parentheses

*significant at $5 \% ; * *$ significant at $1 \%$ 
Table 9

The number of firms in the sample that reach the critical level of international diversification

\begin{tabular}{|c|c|c|c|}
\hline \multicolumn{4}{|c|}{ low tech } \\
\hline & OLS & median & robust outlier \\
\hline optimal point & 25 & 20 & 23 \\
\hline percentage reached optimal point & 0 & $1.60 \%$ & $1.60 \%$ \\
\hline 95\% CI (high and low values) & {$[8,41]$} & {$[16,24]$} & {$[14,32]$} \\
\hline percentage fall in the 95\% CI & $6.42 \%$ & $2.72 \%$ & $2.72 \%$ \\
\hline
\end{tabular}

\begin{tabular}{|c|c|c|c|}
\hline \multicolumn{4}{|c|}{ Medium - low tech } \\
\hline & OLS & median & robust outlier \\
\hline optimal point & 19 & 19 & 21 \\
\hline percentage reached optimal point & 0 & 0 & 0 \\
\hline 95\% CI (high and low values) & {$[15,23]$} & {$[16,23]$} & {$[15,27]$} \\
\hline percentage fall in the 95\% CI & $4.05 \%$ & $2.70 \%$ & $4.05 \%$ \\
\hline
\end{tabular}

\begin{tabular}{|c|c|c|c|}
\hline \multicolumn{5}{|c|}{ Medium - high tech } \\
\hline & OLS & median & robust outlier \\
\hline optimal point & 32 & 33 & 37 \\
\hline percentage reached optimal point & 0 & 0 & 0 \\
\hline 95\% CI (high and low values) & {$[10,54]$} & {$[21,44]$} & {$[22,51]$} \\
\hline percentage fall in the 95\% CI & $8.98 \%$ & $1.68 \%$ & $1.68 \%$ \\
\hline
\end{tabular}

\begin{tabular}{|c|c|c|c|}
\hline \multicolumn{4}{|c|}{ High tech } \\
\hline & OLS & median & robust outlier \\
\hline optimal point & 14 & 15 & 13 \\
\hline percentage reached optimal point & 0 & 0 & 0 \\
\hline 95\% CI (high and low values) & {$[9,19]$} & {$[9,22]$} & {$[10,17]$} \\
\hline percentage fall in the 95\% CI & 0 & 0 & 0 \\
\hline
\end{tabular}




\section{References}

Bartlett, C. A. and Ghoshal, S. (1986). 'Tap your subsidiaries for global reach'. Harvard Business Review, 64(6): 87-94.

Belderbos, R. and Sleuwaegen, L. (2005) 'Competitive Drivers and International Plant Configuration Strategies: A Product Level Test. Strategic Management Journal, forthcoming.

Benvignati, A.M. (1987). Domestic profit advantages of multinational firms. Journal of Business, 60, 449-461.

Berry, H. (2002) The influence of location and multinational network effects on firm value. Evidence from US manufacturing firms, 1981-2000. Working Paper 2002-07, Jones Centre, The Wharton School.

Braunerhjelm, P. (1996). The relation between firm-specific intangibles and exports. Economic Letters, 53, 213-219.

Bodnar, G.M., Tang,C. and Weintro, J. (2000). Both sides of corporate diversification: the value impacts of geographic and industrial diversification. Working paper, John Hopkins University, Baltimore, MD.

Buchinski, M. (1998). Recent advances in quantile regression models. Journal of Human Resources, 33, pp. 88-126.

Cantwell, J.A. and Piscitello, L. (2005) The Recent Location Of Foreign R\&D activities by large MNCs in the European regions. the role of different sources of spillovers. Regional Studies, 39 (1) pp 1-16.

Capar, N. and Kotabe, (2003) The relationship between international diversification and performance in service firms. Journal of International Business Studies, 34, 345-355.

Contractor, F.J., Kundu, S.K. and Hsu, C-C. (2003) A three stage theory of international expansion: the link between multinationality and performance in the service sector. Journal of International Business Studies, $34,5-18$.

Coughlin, C.C. and Segev, E. (2000) Location determinants of new manufacturing plants. Journal of Regional Science, 40, 323-351.

De Propris, L. Driffield, N. L. and Menghinello, S. (2005). 'Local industrial systems and the location of FDI in Italy', International Journal of the Economics of Business, 21(1): 105-121

Doukas, J.A. and Lang, L.H.P. (2003) Foreign direct investment, diversification and firm performance. Journal of International Business Studies, 34 (2) 153-172.

Dunning, J.H. (1988). 'The Eclectic Paradigm of International Production: A Restatement of some possible Extensions'. Journal of International Business Studies. 19 (1) pp. 1-29.

Dunning, J. H. (1998) 'Location and multinational enterprise: A neglected factor', Journal of International Business Studies. 29(1): 45-66.

Geringer, J., Beamish, P., and da Costa, R. (1989). 'Diversification strategy and internationalization implications ofor MNC performance', Strategic Management Journal, 10(1): 109-119.

Girma, S., Greenaway, D. and Wakelin, K. (2001). Who benefits from foreign direct investment in the UK? Scottish Journal of Political Economy, 48, 119-133.

Girma, S., Greenaway, D and Kneller, R. (2004b) Entry to Export Markets and Productivity: A Microeconometric Analysis of Matched Firms, Review of International Economics, 12, 855-66 Grant, R.M (1987). Multinationality and performance among British manufacturing companies. Journal of International Business Studies, 18 , 79-89.

Griffith, R. and Simpson, H. (2002). Characteristics of foreign-owned firms in British manufacturing. In R. Blundell, D. Card and R. Freeman (eds.), Creating a Premier League Economy, Chicago: Chicago University Press.

Griliches, Z. and Maireisse (1995) Production functions: The search for identification. NBER working papers, no. 5067.

Gomes, L. and Ramaswamy, K. (1999). An empirical examination of the form of the relationship between multinationality and performance. Journal of International Business Studies, 30, 173-188. 
Hitt, M.A. , Hoskisson,R.E and Kim, H. (1997). International diversification: effects on innovation and firm performance in product diversified firms. Academy of Management Journal, 40, 767-798. Hitt, M.A., Jammine, J.P. and Thomas, H. (1988) . Diversity, diversification and profitability among British manufacturing companies. Academy of Management Journal, 40, 767-798.

Hymer, S.H. (1976) . The International Operations of National Firms: A Study of Direct Foreign Investment. Boston: MIT press.

Kindleberger, C.P. (1969). American Business Abroad: Six Lectures on Direct Investment. New Haven: Yale University Press.

Kogut B (1985). Designing global strategies: profiting from operational flexibility. Sloan Management Review, 26, 27-38.

Kotabe, M., Srinivasan, S.S. and Aulakh, P.S. (2002) Multinationality and firm performance: The moderating role of R\&D and marketing capabilities. Journal of International Business Studies, 33, 79-97.

Kogut, B (1985). Designing global strategies: profiting from operational flexibility. Sloan Management Review, 26, 27-38.

Laafia, I. (2002) Employment in high tech and knowledge intensive sectors in the EU continued to Grow in 2001; EUROSTAT, Statistics in Focus: Science and Technology, 9(4).

Levinsohn, J (1993). 'Testing the imports-as-market-discipline hypothesis', Journal of International Economics, 35, 1-22.

Levinsohn, J. and Petrin, A. (2003). Estimating production functions using inputs to control for unobservables. Review of Economic Studies, 70(2). -317-342.

Mathur, I. , Singh, M. and Kinberly, C.G. (2001). The evidence from Canadian firms on multinational diversification and performance. The Quarterly Review of Economics and Finance, $41,561-578$.

Nickell, S. J. (1996) 'Competition and corporation perforce', Journal of Polital Economiest, 104(7), 724-

Olley, G. S. and Pakes, A., (1996) 'The dynamics of productivity in the telecommunications equipment industry'. Econometrica, 64, 1263-1297.

Porter, M. E. (1986). 'Changing patterns of international competition', California Management Review, 28(2): 9-40.

Pearce, R.D. (1999). Decentralised R\&D and strategic competitiveness: globalised approaches to generation and use of technology in multinational enterprises (MNE's), Research Policy, Vol.28, $157-178$.

Ramsawamy, K. (1995). 'Multinationality, configuration and performance: A study of MNEs in the US drugs and pharmaceutical industry', Journal of International Management, 1(2):231-253.

Rousseeuw, P. J. and A. M. Leroy (1987), Robust Regression and Outlier Detection, John Wiley, New York

Siotis G (1999) 'Foreign direct investment strategies and firms' capabilities', Journal of Economics and Management Strategy, 8, 251-70.

Tallman, S. and Li, J. (1996) Effects of international diversity and product diversity on the performance of multinational firms. Academy of Management Journal, 39(1): 179-196.

UNCTAD (1998) World Investment Report 1998 - Trends and Determinants. UNCTAD, Geneva.

UNCTAD (2002) World Investment Report 2002 - Transnational Corporations and Export Competitiveness. UNCTAD, Geneva.

UNCTAD (2004) World Investment Report 2004 - The Shift Towards Services. UNCTAD, Geneva.

Zaheer, S. and Manrakhan, S. (2001), 'Concentration and Dispersion in Global Industries: Remote Electronic Access and the Location of Economic Activities', Journal of International Business Studies, 32(4): 667-686.

\section{Figure 1.}




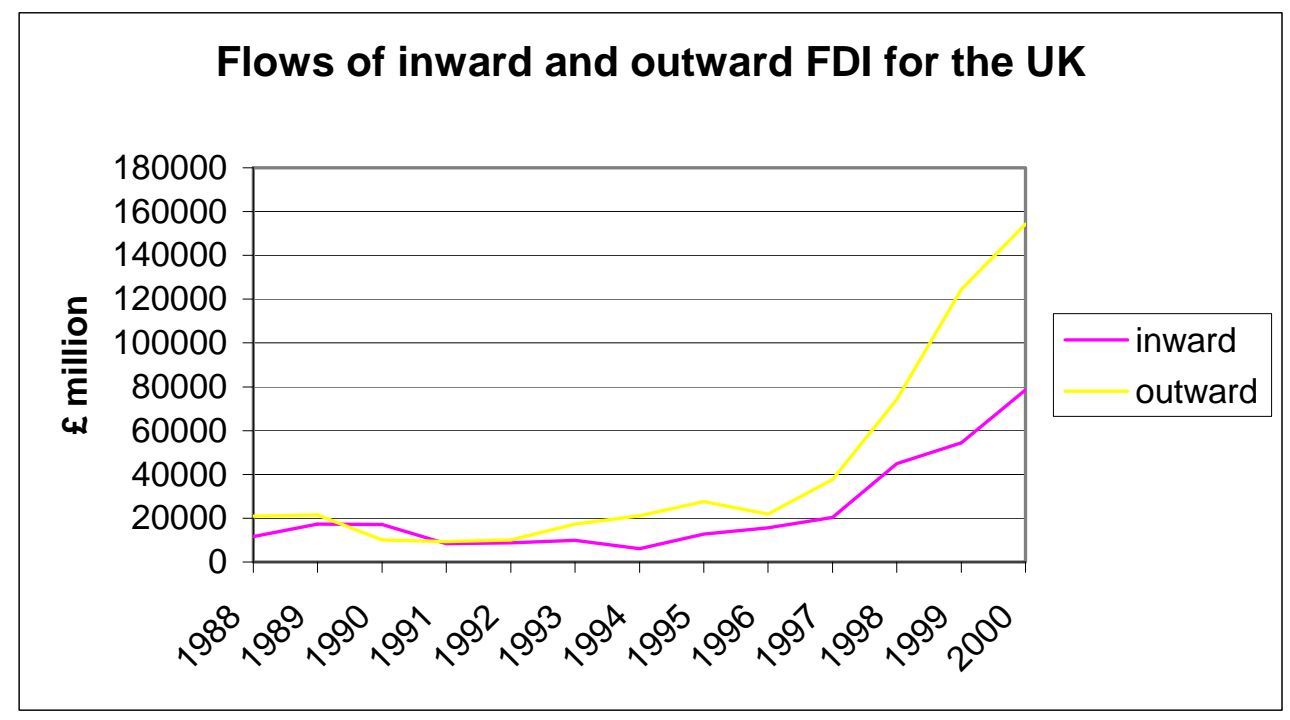

Source: Office of National Statistics, Business Monitor MA4: Foreign Direct Investment, various years.

${ }^{\mathrm{i}}$ The authors wish to acknowledge the support of the ESRC under award number RES-000-22-0468. We would also express our thanks to Davide Castellani and other participants at the UK AIB conference, as well as to Jim Love and Bruce Blonogen conference for comments on an earlier draft.

${ }^{\text {ii }}$ While the use of "high tec", "low tec" etc. is always rather arbitrary, the classification we employ is the definition of technological intensity is based on an OECD-EUROSTAT classification (Laafia, 2002) and distinguishes four types of manufacturing industries: high technology, medium-high technology, medium-low technology and low technology industries (see Appendix B).

iii This method is an extension of the method developed by Olley and Pakes (1996) which uses a function of investment as proxy of the productivity shock.

${ }^{\text {iv }}$ See Appendix A for details on the construction of the estimate of total factor productivity.

${ }^{\mathrm{v}}$ Imports penetration is defined as imports divided by domestic output + imports - exports.

${ }^{\text {vi }}$ Thus in contrast to OLS, the sum of the absolute values of the residuals is minimised, and for this reason this method is also known as the Least Absolute Deviations regression.

vii Sourafel Girma wishes to express his gratitude to Davide Castellani and Antonello Zanfei for allowing him to use some information from this database. 